\title{
Parametric Design and Finite Element Analysis of Involute Helical Gears
}

$$
\begin{array}{r}
\text { Jian ZHANG } \\
\text { 1, a } \\
\text {, XHANG } \\
\text { ZHemei } \\
\text { QI, }
\end{array}
$$

${ }^{1}$ School of Transportation and Automobile Engineering, Panzhihua University, Panzhihua 617000, China;

${ }^{2}$ School of Mechanical Engineering, Panzhihua University, Panzhihua 617000, China

azhangjianpzh@126.com, b9237931@qq.com, '604627144@qq.com

Keywords: involute helical gear gears; Pro/E; ANSYS; finite element.

Abstract. The establishing for involute helical cylindrical gear and involute helical bevel gear were completed based on Pro/E. The simulation for assembly and operation was also accomplished for them. The modal analysis, static analysis and the dynamic contact transient analysis for the involute helical gears were finished by using ANSYS. The statics analysis results showed that on the premise of the same load the equivalent stress of involute spiral bevel gear and other principal stress were larger than involute helical cylindrical gear. The dynamic contact analysis showed that the involute helical gear tooth surface contact stress in the meshing process gradually became larger and then gradually became smaller. The contact stress distribution was mainly concentrated in the ends of the gear, so we should pay attention in the design and use.

\section{Introduction}

Involute helical gear helical gear transmission is stable. Its impact and vibration are small. It is suitable for high speed, heavy load transmission, widely used in production and life [1-2]. However, with the development of mechanical discipline, gear has the development of heavy load and high speed, low noise, high reliability. Modern gear design of the gear transmission system's static and dynamic characteristics put forward to higher requirements, some scholars of home and abroad do some research on modeling and grinding of involute helical gears forming [3-5]. In order to study the involute helical gear better, using a method of parametric design of involute helical gear based on Pro/E [6], the rapid establishment of involute helical cylindrical gears and the involute spiral bevel gear model. Then the ANSYS software is used to analyze the mechanical characteristics of the two kinds of gear models, and provide a reference for the design and application of the involute helical gears.

\section{Parameter equation of involute helical gears}

\section{Parameter equation of involute}

In Pro/E, the parameter equation of involute in Descartes coordinate system is:

$\mathrm{R}_{0}=\frac{\mathrm{d} \mathrm{b}}{2} / *$ Circle radius of involute helical gear $* /$

thet a $=\mathrm{t} \cdot 45 / *$ Cylindrical coordinate angle $* /$

$X=\frac{R_{0} \cdot \cos (\text { theta })+R_{0} \cdot \sin (\text { thet } a) \cdot \text { theta } \cdot p i}{180} / * X$ coordinate value of Descartes coordinate

system */

$Y=\frac{R_{0} \cdot \sin (\text { theta })-R_{0} \cdot \cos (\text { theta }) \cdot \text { theta } \cdot \text { pi }}{180} / * Y$ coordinate value of Descartes coordinate

system */

$Z=0 \quad / * Z$ coordinate value of Descartes coordinate system */

The parameter equation of involute in cylindrical coordinate system: 
$R_{0}=\frac{d b}{2}$

af a $=60 \cdot t / *$ Parameter variation range $* /$

$r=\sqrt{\left(R_{0}{ }^{2}+\left(p i \cdot R_{0} \cdot a f a \div 180\right)^{2}\right)}$

thet $a=a f a-a \tan \left(\frac{p i \cdot R_{0} \cdot a f a}{R_{0} \cdot 180}\right)$

\section{Involute spiral surface tooth surface equation}

In Pro/E, the spiral surface equation is:

$$
\begin{gathered}
x_{1}=R_{b} \cos (\beta+\alpha+\theta)+R_{b} \alpha \sin (\beta+\alpha+\theta) \\
y_{1}=R_{b} \sin (\beta+\alpha+\theta)-R_{b} \alpha \cos (\beta+\alpha+\theta) \\
z_{1}=P \cdot \theta
\end{gathered}
$$

The normal equation of helix is:

$\mathrm{n}_{\mathrm{x}}=\mathrm{PR}_{\mathrm{b}} \alpha \sin (\beta+\alpha+\theta) / \mathrm{Rb} / *$ Circle radius of involute helical gear $* / \mathrm{P} / *$ Helical parameters *

$n_{y}=-P R_{b} \alpha \cos (\beta+\alpha+\theta)$

$n_{z}=R_{b}{ }^{2} \alpha$

\section{Helix parameter equation}

In Pro/E, the Descartes coordinate spiral line parameter equation is:

$$
\begin{aligned}
& R_{0}=\frac{m \cdot t \cdot Z}{2} \\
& C_{0}=\frac{B \cdot \tan (b t)}{R_{0} \cdot 180 \cdot p i} \\
& X=R_{0} \cdot \cos \left(\cdot C_{0}\right) \\
& Y=R_{0} \cdot \sin \left(t \cdot C_{0}\right) \\
& Z=\frac{R_{0} \cdot t \cdot C_{0} \cdot p i}{180 \cdot \tan (b t)}
\end{aligned}
$$




\section{Parametric modeling of involute helical gears}

Because of the difference of the shape of between involute helical cylindrical gear and involute spiral bevel gear, a few parameters are modified in the modeling process. This model has little effect on the results of finite element analysis.

Based on the data in Table1, the 3D model of involute helical cylindrical gear and involute spiral bevel gear are obtained by modeling in Pro/E.

Table 1 Basic parameters of involute helical gears

\begin{tabular}{lllccc}
\hline \multicolumn{2}{l}{ Basic parameters of involute helical cylindrical gears } & \multicolumn{3}{c}{ Basic parameters of involute spiral bevel gears } \\
\hline Name & Value & Explanation & Name & Value & Explanation \\
\hline $\mathrm{m}$ & 3 & modulus & $\mathrm{m}$ & 3 & modulus \\
$\mathrm{Z}$ & 20 & teeth & $\mathrm{Z}$ & 11 & Pinion \\
$\mathrm{PA}$ & 20 & Pressure angle & Z_ASM & 30 & Big gear \\
$\mathrm{HAX}$ & 1 & Addendum coefficient & ALPHA & 20 & Pressure angle \\
$\mathrm{CX}$ & 0.25 & Top gap coefficient & B & 20 & Tooth width \\
$\mathrm{x}$ & 0 & Coefficient of variation & HAX & 1 & Addendum coefficient \\
$\mathrm{BT}$ & 25 & Helix angle & CX & 0.25 & Top gap coefficient \\
B & 30 & Tooth width & x & 0 & Coefficient of variation \\
& & BETA & & 40 & Helix angle \\
\hline
\end{tabular}

The helix equation is modified to:

$$
\begin{aligned}
& R_{0}=\frac{d b}{2} \\
& C_{0}=\frac{B \cdot \tan (b t)}{R_{0} \cdot 180 \cdot p i} \\
& X=R_{0} \cdot \cos \left(\cdot C_{0}\right) \\
& Y=R_{0} \cdot \sin \left(t \cdot C_{0}\right) \\
& Z=\frac{-R_{0} \cdot t \cdot C_{0} \cdot p i}{180 \cdot \tan (b t)}
\end{aligned}
$$

In the Pro/E model, another involute helical cylindrical gear is obtained, and then the alignment constraints are added to assemble and run the simulation. Similarly, the simulation model of involute spiral bevel gear assembly is established. The simulation models of two pairs of gear assembly are shown in Fig.1.

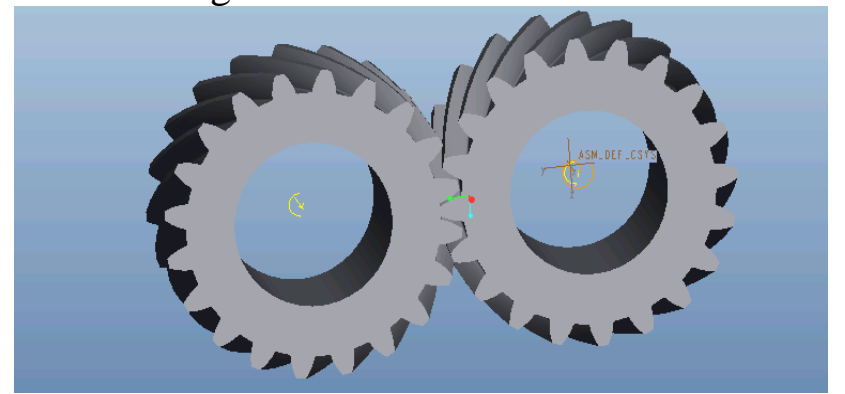

(a) involute helical cylindrical gears

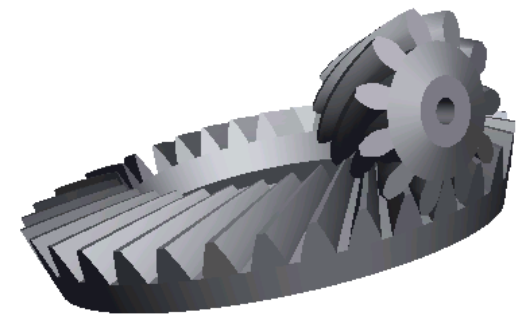

(b) involute spiral bevel gears

Fig.1 Meshing simulation of involute helical gears 


\section{Finite element analysis of involute helical gears}

\section{Modal analysis of involute helical gears}

Modal analysis is a modern method to study the structures dynamic characteristics, and the application of system identification method in the field of Engineering Vibration.

Modal analysis of involute helical cylindrical gear and involute spiral bevel gear in ANSYS is carried out. Elastic modulus E $=2 * 10^{11} \mathrm{~N} / \mathrm{m} 2$, Poisson's ratio $\mu=0.3$ and Density $\rho=7850 \mathrm{~kg} / \mathrm{m} 3$ are defined and imported model. After the meshing of the involute helical gear, a cylindrical constraint is added. Let the gear run at $75 \mathrm{rad} / \mathrm{s}$, and 6 order modal number are defined. Then the natural frequency of gear within different modes are obtained, as shown in Table2.

Table 2 Natural frequencies of gears under different modes of involute helical gears

\begin{tabular}{cccc}
\hline \multicolumn{2}{l}{ Involute helical cylindrical gear } & \multicolumn{2}{c}{ Involute spiral bevel gear } \\
\hline Modality & frequency $(\mathrm{Hz})$ & Modality & frequency $(\mathrm{Hz})$ \\
\hline 1 & 7.85092 & 1 & 11.906 \\
2 & 26120.7 & 2 & 22620 \\
3 & 26121.3 & 3 & 29949 \\
4 & 41506.0 & 4 & 33152 \\
5 & 41520.6 & 5 & 36447 \\
6 & 44513.8 & 6 & 38949 \\
\hline
\end{tabular}

\section{Statics analysis of involute helical gears}

It is very necessary and important to study the gear static characteristics and optimize its design, which can save materials, reduce cost, shorten development cycle, improve the gear performance life and work efficiency[7-8].

Elastic modulus $\mathrm{E}=2 * 10^{11} \mathrm{~N} / \mathrm{m} 2$, Poisson's ratio $\mu=0.3$, and density $\rho=7850 \mathrm{~kg} / \mathrm{m} 3$ defined in the static analysis module of ANSYS, are imported into two assembled gears. the two-gear tooth and alveolar contact with surface-to-surface. When we add constraint, one gear is fixed, another gear is added a cylindrical constraint, and then a $1000 \mathrm{~N} \cdot \mathrm{mm}$ torque is exerted on the gear rotating around the axis. The stress distributions of the static contact are calculated, as shown in Fig. 2.

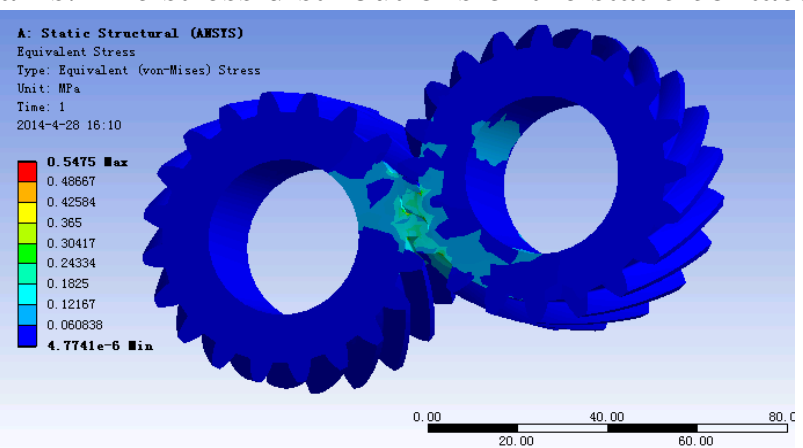

(a) involute helical cylindrical gears

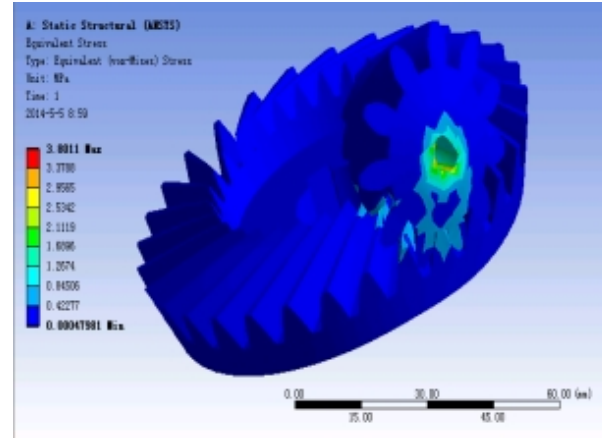

(b) involute spiral bevel gears

Fig. 2 Distribution of equivalent stress of involute helical gears

According to the involute helical cylindrical gear and involute spiral bevel gear static comparative analysis, we can see that under the same load the equivalent stress of involute spiral bevel gear and other principal stress are higher than the involute helical cylindrical gear.

\section{Dynamic contact transient analysis of involute helical cylindrical gears}

Gear dynamic contact analysis reflects better actual-work conditions, because involute spiral bevel gears and the involute helical cylindrical gear belong to the same class of involute helical gear, and their dynamic contact movement are roughly the same. Based on the above reasons, we only analyze the involute helical cylindrical gear dynamic contact transient .

After importing the gears into ANSYS software, when a constraint is applied, a rotation speed is applied to a gear to rotate around the center axis of the gear, and it uniformly increase with the size of $15 \mathrm{rad} / \mathrm{s}$. And another gear is exerted a load torque whose size is $1 * 105 \mathrm{~N} \cdot \mathrm{mm}$, direction is opposite 
to the above gear rotation direction. The distribution figure of the stress in the dynamic contact engineering can be obtained by solving the gear stress distribution. In order to observe intuitively the gear stress change, the maximum stress distribution of the gear meshing cycle can be obtained, as shown in Fig. 3. At the beginning of meshing, the maximum contact stress is $242.38 \mathrm{Mpa}$, and the maximum contact stress is concentrated on inside of alveolar medial. After turning an angle at the time of $0.05 \mathrm{~s}$, the contact point has been moved, and the gear begins the formal meshing. Then the maximum stress is $188.86 \mathrm{Mpa}$. At the time of $0.065 \mathrm{~s}$, when a tooth of the gear completely gets out of meshing and the next tooth just begins contact, at this moment the gear contact stress reaches the maximum value of $355 \mathrm{Mpa}$ during whole meshing cycle. At the time of $0.1 \mathrm{~s}$, the gear begins begin to enter into the next meshing, and the maximum contact stress is $178.92 \mathrm{Mpa}$.

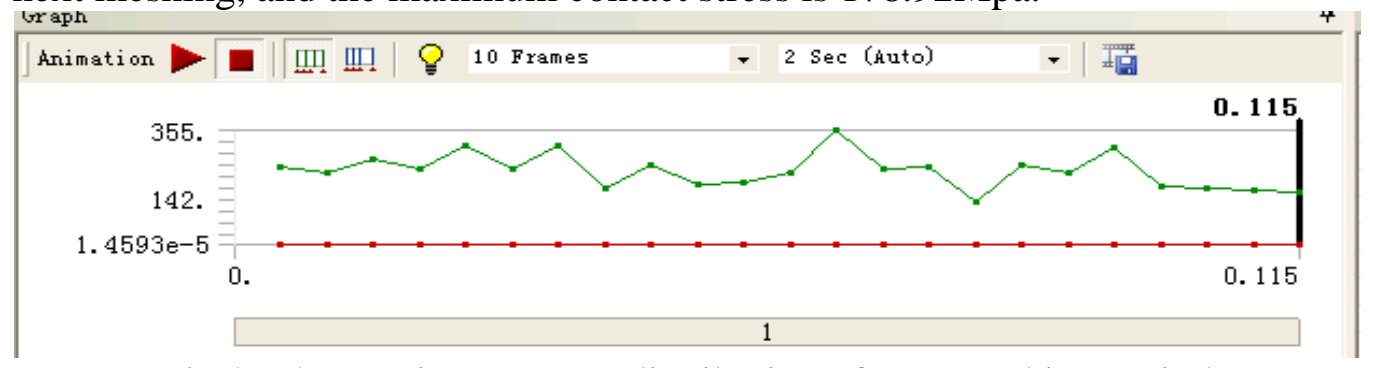

Fig.3 The maximum stress distribution of gear meshing period

In Fig. 4, we can see that the distribution of contact stress is mainly concentrated on both ends of two gears, which suggests that these areas are easy to be worn and broken, so that there are certain requirement limitations on materials .
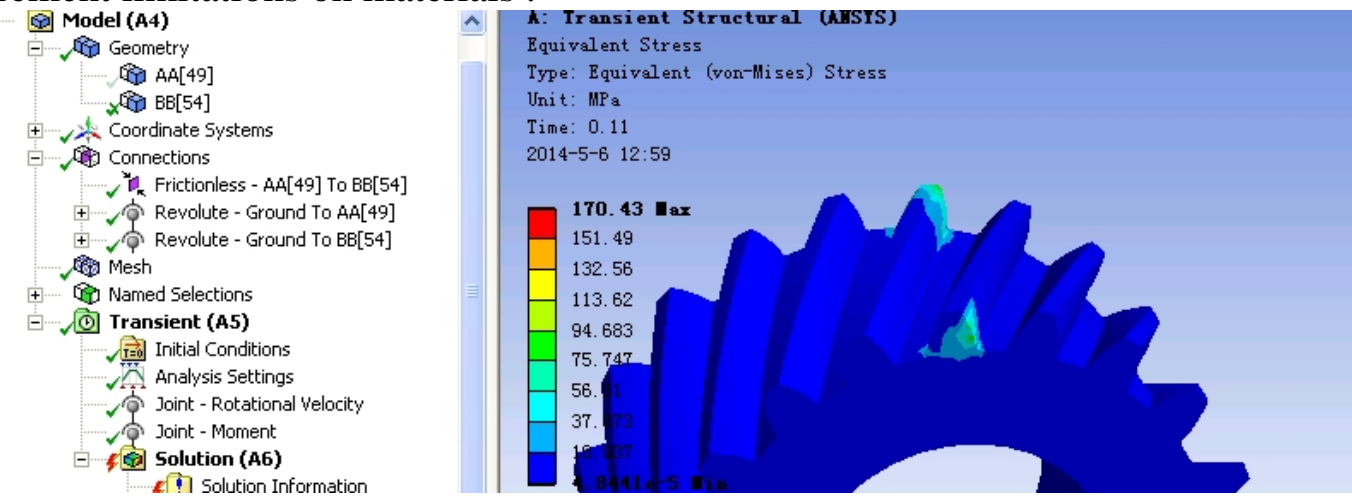

Fig.4 Stress concentration distribution of involute helical gear

Calculation of contact stress of gears based on Hertz formula [9]

$$
\sigma_{H}=\sqrt{\frac{1}{\pi\left(\frac{1 \mu_{1}^{2}}{E_{1}}+\frac{1 \mu_{2}^{2}}{E_{2}}\right)}} \sqrt{\frac{2}{\cos ^{2} \alpha \tan \alpha}} Z_{E} \times \sqrt{\frac{2 K T_{1}}{b d_{1}^{2}} \times \frac{u+1}{u}}=328 M p a
$$

The maximum gears stress calculated in ANSYS is close to $\sigma_{\mathrm{H}}$, and the difference between them is not more than 5\%, so the error range is within the allowable range. It can be seen from Fig. 4 that The results of finite element analysis are closer to the actual situation.

\section{Conclusions}

(1) The 3D parametric models of involute helical cylindrical gear and involute spiral bevel gear are constructed Based on the Pro/E platform,. Through the modal analysis of the model, the natural frequency of the gear under different models is obtained, which provides the parameter basis for the use of the involute helical gear in different working conditions.

(2) The static analysis of involute helical cylindrical gear and involute spiral bevel gear is carried out. The results show that the equivalent stress and other principal stress of involute spiral bevel gear are greater than involute helical gear under the same load.

(3) Through the dynamic contact analysis of involute helical gear and involute helical gear 
stress concentration distribution, on the one hand, it can be found that the maximum involute helical cylindrical gear contact stress in meshing process gradually became larger and then gradually became smaller, which reflects the distribution of stress distribution in addition to the maximum contact stress. On the other hand, the distribution of contact stress is mainly concentrated on both ends of the gear, and these areas are easy to be worn and broken, so there must be certain requirement limitations on materials.

\section{Acknowledgements}

This work was financially supported by the Education Department of Sichuan province in 2016 scientific research program of natural science project (16ZB0482) and the national innovation training program for college students (201411360016).

\section{References}

[1] Zhanglai Lv, Zhifeng Li. Study on Profile of Grinding Wheel for Processing Involute Helical Gear [J]. MACHINE TOOL \& HYDRAULICS, 2014,42 (1): 17-19,30.

[2] Shue Song, Zhihui Shi. Research on The Method of Parametric Modeling for Involute Helical Gear Based on Pro/Engineer [J]. Journal of Dalian Jiaotong University, 2010 (1): 34-36.

[3] Xiaofei Wang, Zhifeng Li, Gaoyong WANG, etc. Form Grinding Wheel Dressing for the Involute Helical Gear [J]. Modular Machine Tool \& Automatic Manufacturing Technique, 2013, (4):134 -138 .

[4] Jianjun Song, Tengjiao Lin, Qing Wang, etc. Contact Fatigue Analysis and Modification Influence Research of Involute Helical Gear Pair With Crossed Axis [J]. Machine Design and Research, 2015,31 (2): 41-45.

[5] Wei Sun, Dongsheng Zhang, Xiaofei Wang. Research on the Involute Helical Gear Based on Form Grinding [J]. Mechanical Research and Application, 2016,29 (3): 13-16, 19.

[6] Jian Zhang, Linze Li, The Establishing and Structural Analysis for Globoid Indexing Cam Based on Pro / E [J]. Modular Machine Tool \& Automatic Manufacturing Technique,2013 (7): 41-43.

[7] Xuemei Qi. Modeling and Dynamic Analysis Belt Drive in planetary transmission system[J]. Mechanical Transmission ,2015,39 (2): 80-83.

[8] Jian Zhang, Lin Chen, Qi Zhang, etc. Parametric Design and Finite Element Analysis of "S"shaped Gear [J]. Modular Machine Tool \& Automatic Manufacturing Technique, 2015, (3): 44-47.

[9] Hongwen Liu. Mechanics of Materials [M]. Beijing: Higher Education Press, 2011. 